\title{
Do we know bad science when we see it?
}

\author{
David R. Jones, MD
}

\author{
From the Thoracic Surgery Service, Memorial Sloan Kettering Cancer Center, New York, NY. \\ Disclosures: Author has nothing to disclose with regard to commercial support. \\ Received for publication July 9, 2015; accepted for publication July 10, 2015; available ahead of print Aug 5, \\ 2015 . \\ Address for reprints: David R. Jones, MD, Thoracic Surgery Service, Memorial Sloan Kettering Cancer Center, \\ 1275 York Ave, New York, NY 10065 (E-mail: jonesd2@mskcc.org). \\ J Thorac Cardiovasc Surg 2015;150:472-3 \\ 0022-5223/\$36.00 \\ Copyright $(2015$ by The American Association for Thoracic Surgery \\ http://dx.doi.org/10.1016/j.jtcvs.2015.07.032
}

\section{In questions of science, the authority of a thousand is not worth the humble reasoning of a single individual.} -Galileo Galilei, The Assayer ${ }^{1}$

Regardless of specialty, as physicians, we all strive to use evidence-based medicine when caring for our patients. Unfortunately, most of our practice is not based on level-I data, and therefore, we rely on lesser degrees of evidence, such as large retrospective case series, phase-II trials, or nonrandomized studies. In particular, oncology physicians and their patients benefit when randomized phase-III studies reach accrual, and the results lead to improvements in the diagnosis, treatment, and survivorship of our patients. What is rarely discussed is when care is modified based on inadequately powered studies, post hoc analyses, or premature analysis of studies. One would think that this should be a "never event" with investigators, institutional review boards, biostatisticians, and journal editors who collectively monitor these processes. But such events do happen, in oncology and likely other specialties.

In this edition of the Journal, the expert opinion of Meyers and colleagues ${ }^{2}$ raises serious concerns about a recent paper and editorial in Lancet Oncology $y^{3}$ regarding the use of stereotactic ablative radiotherapy (SABR) compared with lobectomy for operable clinical stage-I non-small cell lung cancer (NSCLC). The authors report the combined results of 2 failed, multicenter, international phase-III randomized trials (STARS \& ROSEL), in which the number of events was too low to reach clinical significance, and the total number of evaluable patients $(n=58)$ for both studies was vanishingly low. Based on an improved overall survival at 3 years, with SABR compared with lobectomy, and fewer treatment-related adverse events with SABR, the authors conclude that SABR could be an option for patients with operable stage-I NSCLC. As pointed out by Meyers and colleagues, ${ }^{1}$ the data do not support the conclusions. Perhaps more importantly, they suggest that the above-described monitoring system missed the mark and permitted publication of this paper which, depending on the lens, could be construed to suggest that SABR is equivalent, if not superior, to anatomic resection for clinical

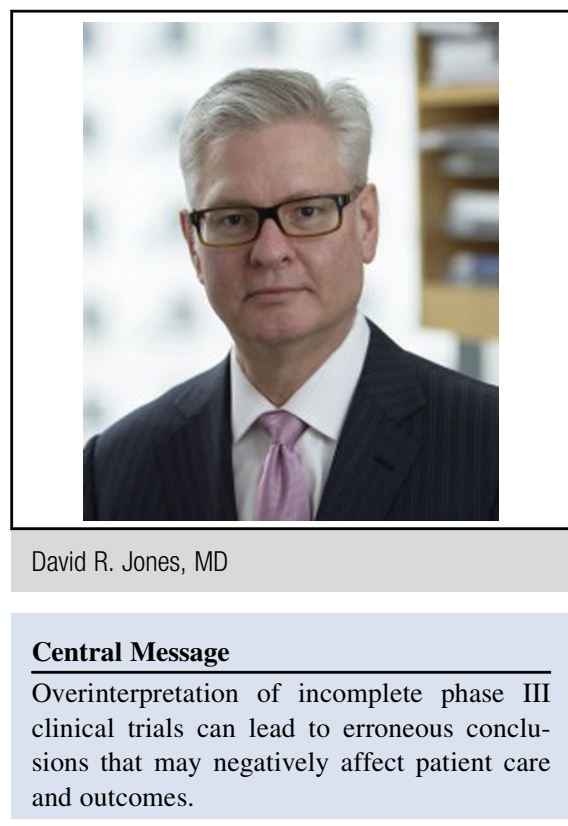

See Article page 468 .
stage-I NSCLC. I agree with the assessment of Dr Meyers and colleagues and their "humble reasoning."

However, if we move beyond the issue of a misguided paper espousing conclusions that are not supported by data, we are still left with the question of what the evidence is for SABR in this select patient population. Clearly, we do not have equipoise among enrolling investigators and medical specialties and patients regarding this question. More phase-III studies, as called for by the authors of the Lancet Oncology editorial ${ }^{3}$ and the paper, ${ }^{2}$ will most certainly not be successful and likely will not be funded, unless by industry. Why is equipoise lacking? Although the reasons are multiple (ie, training and institutional biases), I believe the primary reason is financial. If radiation oncologists and surgeons were reimbursed identically for the initial treatment of clinical stage-I NSCLC, the likelihood of meeting accrual for trials, such as STARS and ROSEL, would likely be higher. Given that such an accrual is not likely to occur, we need a better way to answer the question of which local modality therapy is most beneficial for these patients. When we do that, we will have to accept that the evidence will most certainly not be level-I evidence.

One suggestion is to have an audited international registry of both SABR and pulmonary lobectomy patients at selected and vetted institutions, with strict reporting requirements for data elements, such as pulmonary function 
studies, comorbid conditions, tumor size, location, fluorodeoxyglucose-positron emission tomography findings, and outcomes. Although this type of approach is problematic for several reasons, these data may be the best that can be generated to guide physicians and their patients with clinically early-stage NSCLC. I would argue that, if done correctly, these data would be better than those provided by the Lancet Oncology paper. ${ }^{3}$

In his publication The Assayer, the Italian scientist Galileo is widely credited with establishing how quality science should be performed. Phase-III randomized trials with adequate power and follow-up certainly meet the requirements set forth in Galileo's scientific manifesto. Dr Meyers and colleagues ${ }^{2}$ are correct to shine a light on studies that fail to meet that mark.

\section{References}

1. Galilei G. The Assayer. In: Stillman D, trans. Discoveries and Opinions of Galileo. New York: Doubleday \& Co; 1957:237-8

2. Meyers BF, Puri V, Broderick SR, Samson P, Keogan K, Crabtree TD. Lobectomy versus stereotactic body radiotherapy for stage I non-small cell lung cancer: post hoc analysis dressed up as level I evidence? J Thorac Cardiovasc Surg. 2015;150: 468-71.

3. Chang JY, Senan S, Paul MA, Mehran RJ, Louie AV, Balter P, et al. Stereotactic ablative radiotherapy versus lobectomy for operable stage I non-small cell lung cancer: a pooed analysis of two randomized trials. Lancet Oncol. 2015;16:630-7. 